face throughout; $(b)$ the vesicles were mostly hemispherical, tense and ranging in size up to that of a split pea, showing in some cases slight umbilication, in some cases the fully developed vesicle resembling that of variola, in others that of varicella; (c) a pustular stage occurred only at times and does not seem to have been constant. This was followed by the formation of crusts, and these on separation left cicatrices which were still present when the cases were examined some months later. 6. The various stages of the eruption were observed at the same time closely associated on the same parts of the body. 7. The disease occurred equally in vaccinated and unvaccinated subjects, as well as in those who were deeply pitted by antecedent small-pox. Dr. Anderson's description contains symptoms not observed in the cases which came under observation at the Belvidere Hospital. In his patients (1) the date of appearance of the eruption as stated in his paper is a little indefinite, but it seems in some instances to have appeared in the course of the third day; (2) no mention is made of the persistence of papules and the whole of the eruption is said to have vesiculated; and (3) a true pustular stage seems to hare been observed (the nearest approach to this among the cases here dealt with was a seropurulent condition of the contents of some of the eruptive elements). From Dr. Anderson's statement that the pustules ruptured and in some cases gave rise to superficial sores it is quite possible that the purulent condition may have resulted from secondary infection by pyogenic organisms; but, on the other hand, it must be remembered that as Dr. Anderson observed 115 cases it is likely he would have had the opportunity of noting greater variation in the type of the rash than ourselves. A due comparison of the clinical features observed in these cases by us with those set forth in Dr. Anderson's paper warrants the belief that the disease is neither variola nor varicella, but is probably a third disease of a specific character presenting resemblances to both, while at the same time it possesses certain features which entitle it to be placed by itself as a specific entity and bearing the same relation to both the diseases mentioned as exists between the more familiar forms of small-pox and chicken-pox. It is, of course, possible that the condition may be merely a modification of raricella the result of racial difference, and Dr. Anderson gives no clue in his paper as to whether the disease limited its attacks to the dark race or involved the white population also, but as he refers to cases occurring in his private practice similar to those which he observed in the prison and penitentiary it is quite likely that whites as well as negroes were victims of the disease. If this inference be correct then the argument that the clisease is merely a modified varicella due to racial conditions must fall to the ground, although in connexion with this point it must not be overlooked that climatic rather than racial conditions might result in modifying varicella at least to some extent. Our opinion, based upon observation of a large number of cases both of variola and varicella, is that almost certainly the disease should be regarded as a specific entity. This conclusion, if correct, would explain certain peculiarities from time to time reported as occurring among small-pox patients in the East - e.g., susceptibility to vaccinia after passing through what is supposed to have been an attack of small-pox as well as other somewhat anomalous conditions with which we in this country are unfamiliar.

Glasgow.

\section{THE STERILISATION OF CATGUT BY DRY HEAT.}

BY J. H. DAUBER, M.A., M.B., B.CH. OXON., M.R.C.P. LOND.,

PHYSECIAY TO THE HOSPITAL FOR WOMEN, SOHO.

IN the issue of THE LANCET of Oct. 1st Mr. Mayo Robson drew the attention of the profession to his method of sterilising catgut by boiling it in di-methyl-benzene and thence transferring it before use either to a 5 per cent solution of carbolic acid or to methylated spirit. As the details are not known to everyone I should like to mention another method of sterilisation-i.e., that by dry heat, which also has the merits of simplicity and efficacy. It is much in rogue on the continent and also I believe in America. (Boxes and sealed tubes of dry sterilised catout can be purchased at many instrument makers in this country, but personally I have a preference for using, in a matter of such importance, an article the preparation of which need not be taken on trust.)

The following is the method of sterilising catgut adopted by Professor Tscherning of Copenhagen, who recently very kindly showed me the details observed by himself in its preparation at the Kommune Hospital in that city. The ordinary commercial catgut as it comes from the manufacturer is placed on trays in the steriliser between sheets of cellulose paper. It is then heated for six hours consecutively, for the first hour at a temperature of $60^{\circ} \mathrm{C}$., for the second and third hours at $100^{\circ} \mathrm{C}$., and for the fourth, fifth, and sixth at $140^{\circ} \mathrm{C}$. It is then removed, wrapped up and closely sealed in an envelope of cellulose paper which is again placed in another envelope of slightly larger size and similarly closed. The catgut now encased within two firmly sealed envelopes is a second time placed in the steriliser and subjected for another two hours to a temperature of $140^{\circ} \mathrm{C}$. The envelopes are placed in racks in the steriliser and contain various sizes of catgut labelled on the outside, some of a size for ligaturing the pedicle in ovariotomy, others for fine buried sutures or other purposes where absorption is desired within a short period. These envelopes can be taken from the steriliser and placed in the pocket or bag of the operator and need not be opened until the time of operation. Thus they are very handy and portable. It is to be remembered that catgut ligatures prepared by any of the wet methods become, if kept in spirit for any length of time, hard and need more time for absorption. If, on the other hand, they are kept in an antiseptic aqueous solution they tend to become soft and lax, whereas if kept in any preparation of glycerine they are somewhat difficult to manipulate owing to their extreme slipperiness. The dry catgut is without these disadvantages. The method of raising the temperature by slow degrees prevents the catgut becoming brittle-the grease and oil in the gut being driven off gradually at the lower temperatures.

Charles-street, $\mathrm{W}$.

\section{REMOVAL OF A CALCULUS FROM THE COMMON BILE DUCT 2 IN. LONG AND $3 \frac{1}{2}$ IN. IN CIRCUMFERENCE WITH- OUT SUTURING THE DUCT.}

BY H. J. THORNTON, L.R.C.P. LOND., M.R.C.S. ENG., FORMERLY HOUSE SURGEON TO THE MODLESEX HOSPITAL; SURGEON TO THE PASSMORE EDWARDS COTTAGE HOSPITAL, ACTON.

THE patient was a man, aged fifty-eight years, a gold prospector by trade, and was one of the early pioneers of the Western Australian goldfields. $\mathrm{He}$ was a man of splendid build, spare in frame, strong; and active. His life had been full of hardship from rough food, bad water, sc., on his travels. Except accidents he never suffered from any serious illness until four years ago, when being in Adelaide he began to get attacks of pain, vomiting, and slight jaundice. These occurred often at intervals of only a few days, sometimes weeks. Sometimes after attacks he passed small gallstones by the bowel. The pain was so severe that he had to have hypodermic injections of morphia, and it was so continuous about two years ago that he became reduced to an extreme degree of emaciation. After undergoing rest anc medicinal treatment at a hospital in Melbourne, with careful diet, he improved a good deal, but the attacks still recurred at longer intervals, and just previously to coming to England twelve months ago they became of daily occurrence. He stated that he could not prevail upon the Australian surgeons to operate, so he determined to come home. On examination there was distinct tenderness and a sense of obscure fulness over the region of the gall-bladder, but deeper than that organ. Although the patient was very thin, no enlargement of the liver or gall-bladder could be detected on palpation or percussion. The patient was jaundiced, having recovered from a severe attack of biliary colic only a few days previonsly. As the history seemed so plain it was determined to open the gallbladder and to explore the cystic and common bile ducts. 
Mr. Bland Sutton, assisted by myself, chloroform being administered by Mr. Owen Coker, made an incision from the margin of the ribs on the right side clown in a line with the onter border of the rectus muscle, about 3 in. in length, and the peritoneum was incised. There was no enlargement of the gall-bladder but a small stone could be felt in it. 'The gall-bladder was opened and this was removed. It was quite loose in the viscus. Behind the gall-bladder, underneath the liver could be felt indistinctly a large resisting body in the situation of the common bile duct. 'The abdominal' wound was enlarged, the liver was pulled up as high as possible, and the pylorus was pulled aside. After cautiously working down with the finger $\mathrm{Mr}$. Bland Sutton came on the greatly distended common bile duct, and in this, just past the opening of the cystic duct, was felt a large stone. Strong efforts were made to push it back into the gall-bladder or onwards into the bowel, but, owing to its size, without avail. An incision about $1 \frac{1}{2}$ in. long was made in the long diameter of the duct and the stone was easily expressed. It was composed of cholesterin, was $2 \mathrm{in}$. long and $3 \frac{1}{2}$ in round, was quite smooth, ovoid in form, and weighed 7 drachms. There was but slight bleeding. The incision in the duct was not sutured. A large indiarubber drainage-tube was put in down to the bottom of the abdominal wound, the gall-bladder was closed and stitched to the parietes, and the abdominal walls were closed by three layers of sutures-fine silk for the peritoneum, silkworm gut for the muscles and fascia, and silk for the skin and subcutaneous tissues. It was dressed with the usual antiseptic dressing. After the operation the patient suffered a good deal of pain, which was relieved by small hypodermic injections of morphia for the first twentyfour hours. The temperature never rose above $100^{\circ} \mathrm{F}$. and the pulse kept good. There was for the first three days a profuse discharge of bile, at least 2 or 3 pints daily, requiring frequent dressing of the wound. The tube was gradually shortened and it was removed altogether in about seven days. There was no discharge of bile after the third day. The abdominal wound closed by first intention and the patient made an uninterrupted recovery, with the exception that several of the buried silkworm gut sutures caused small abscesses and were gradually in the course of some months brought to the surface and removed quite undissolved. Since the operation he has never had another attack of biliary colic. He has gained $3 \frac{1}{2}$ st. in weight and can eat any ordinary food with impunity. The scar is firm and strong and there is no ventral hernia.

Acton, W.

\section{A CASE OF PY \&MIA TREATED WITH INJECTIONS OF ANTI-STREPTOCOCCIC SERUM.}

BY HERBERT M. RAMSAY, F.R.C.S. EDIN.

A GIRT, aged fourteen years, developed measles on Feb. 27th, 1898. She went on well, it appeared, until March $3 r d$, when, at about 4 A.M., she complained of pain in the right ear. The pain continued to get worse, the child throwing herself about in bed all through the day and night of the 3rd. On the morning of the $4 \mathrm{th}$ the pain got better and the nurse noticed some discharge from the ear. In the evening the temperature was $104^{\circ} \mathrm{F}$. and the patient complained of pain behind the ear. I saw her for the first time on the evening of the 5 th, when her temperature was $105^{\circ}$. She had had a "shivering fit." Her pulse was 120 , the respirations were 24 , and she was very restless. There was some pain behind the right ear, but this was not increased by pressure and there was no redness or swelling there. On examining the ear I found the meatus filled with inspissated pus and débris and on clearing this out the membrane was seen to be white and sodden and there was a perforation situated at the anterior and inferior part of the membrane. After this her temperature fell to $103^{\circ}$ and she had some sleep. The ear was ordered to be kept syringed out with a perchloride of mercury lotion ( 1 in 4000) and a 2-gr. pill of quinine was directed to be given every six hours. When I saw her again on the evening of the 6th the patient's temperature had gone up to $104^{\circ}$ again, her pulse was 120 , and the respirations were 26 . I found that the meatus was again blocked with pus and after cleaning this out her temperature fell during the night to $99^{\circ}$ and there was a profuse discharge from the ear. In spite of her ear being kept well syringed her temperature rose on the evening of the 7 th to $106^{\circ}$. Her pulse was then 130 , the respirations were 30 , and some dulness was detected at the base of both lungs. She still complained of pain behind the ear and the tip of the mastoid was very tender on pressure. On the 8 th her temperature kept at about $103^{\circ}$ and there was free discharge from the ear. She was restless and sick several times after food, but there was no delirium. The quinine was increased to 2 grs. every four hours and she was given a drachm of brandy with each quinine pill. Mr. Bowlby saw the patient with me on the evening of the 8th, and we decicled that there was no immediate indication for opening the mastoid cells. Her temperature was then $105.4^{\circ}$. She complained of pain at the tip of the mastoirl, and this spot was tender on pressure, but there was no pain or tenderness over the mastoid cells and no headache. She was restless but she had no cerebral symptoms and there was no tenderness over the course of the jugular vein. She had been sick several times after her food and she had had a slight rigor. She slept fairly well and was better on the 9 th, but there were patches of dulness all over both lungs, with fine crepitation and tubular breathing. She had a slight cough but very little expectoration. Her temperature in the evening was $104.6^{\circ}$, her pulse was 104 , and the respirations were 32 . On the morning of the 10th her temperature was $99^{\circ}$ but it rose again in the afternoon to $104 \cdot 4^{\circ}$, when Mr. Bowlby again saw her with me. The patient was now very ill and it was decided to open the mastoid cells, which was done at 4.30 P.M. when Mr. Willett administered the chloroform. Mr. Bowlby onened the mastoid cells and found nothing there except some muco-purulent secretion, but not sufficient of this to account for the high temperature, so no attempt was macle to open up the tympanum. The skull was then opened but the dura mater did not bulge and the lateral sinus was evidently not occluded and the wound was therefore closed. The patient took chloroform well and she went to sleep after $\frac{1}{6} \mathrm{gr}$. of morphia had been injected subcutaneously. Her temperature rose to $105^{\circ}$ in the evening, but on the morning of the 11 th it fell to $99.4^{\circ}$ and she seemed to be much better. In the afternoon, however, she had a slight rigor and her temperature rose once more to $105^{\circ}$. The respirations were 38 . On the 12 th she was troubled a good deal by cough and had some purulent expectoration. Her temperature in the morning was $96.4^{\circ}$ and in the evening it was $104.4^{\circ}$. She had well-marked pneumonia in patches over both lungs. Her condition on the 13th and 14th was much the same. The patient was troubled by cough and she was restless and took her nourishment badly. On the night of the 14th she slept very little and complained of pain in her right wrist and hand. The temperature on the morning of the 15th. was $101 \cdot 4^{\circ}$. The right wrist being swollen and very painful it was dressed with belladonna and glycerine and put up on a light cardboard splint. The wound behing the ear was almost healed. She had a rigor in the afternoon and her temperature went up to $104^{\circ}$. On the 16 th and 17 th the patient was very ill. She had frequent rigors and her temperature ranged from $96^{\circ}$ to $105^{\circ}$. She was very sick and restless. On the 18 th the morning temperature was $96^{\circ}$, the pulse was 120 and very weak and the respirations were 32. She was constantly sick and took no notice of anything. Dr. Herringham saw the patient with me at 6 P.M. on the 18th. Her temperature was then $104^{\circ}$ and though the lungs were clearing up she still seemed very ill. It was decided to try injection of anti-streptococcic serum and Dr. Herringham accordingly injected 5 c.c. into the loin. For a short time she complained of pain at the site of the injection, but this soon passed off and she slept well and more naturally. The blood was examined and was found to contain numerous streptococci and a few staphylococci. There were streptococci in the sputum but no organisms were found in the discharges from the ear. On the 19th the patient had three injections of 10 c.c. each of serum at 8.30 A.M., 1 P.M., and 6.30 P.M. She seemed to have improved and she took her nourishment better. The urine was examined; it contained no albumin. On the 20th and 21st she had three injections each day, at 8.30 A.M. and 1.30 and 6.30 P.M. She was now decidedly better, but though she had no rigors her temperature remained high in the evening, though it was lower than it had been. The lungs were clearing up well 